\title{
THE SYSTEM OF VALUES AND STYLES OF SUCCESS IN THE MEDICAL CAREER: A LONGITUDINAL STUDY
}

\section{WALDEMAR BUDZIŃSKI, MACIEJ WALKIEWICZ, and MALGORZATA TARTAS}

\author{
Medical University of Gdańsk, Gdańsk, Poland \\ Faculty of Psychology
}

\begin{abstract}
Objectives: The purpose of the study was to investigate the relation between system values during medical education and styles of success in the medical career. Material and Methods: The participants were first examined when they applied to the medical school. Questionnaires were given to these students each academic year. Medical doctors who had participated in the first phase of the study completed a questionnaire 4 years after their graduation, too. The baseline questionnaire measured the system values. The follow-up questionnaire included measures of quality of life, work stress and burnout, satisfaction with medicine as a career and professional competency. Results: The identified 3 groups of students representing 3 types of careers had been different regarding their preferred terminal values and instrumental values. Out of 3 groups, 2 presented a high risk of burnout. What is more the life goals (terminal values) are relatively stable, but preferable modes of behavior (instrumental values) are likely to change. The most important differences between students who may suffer from burnout later as doctors and those who are at a lower risk are e.g., family security, freedom, happiness, mature love, self-respect, social recognition and wisdom. Conclusions: The Rokeach Value Survey may be applied to identify specific tendencies in the development of medical career. The obtained results may be used by the medical school admission officers as well as resident selection committees in order to identify candidates who may be at risk of professional difficulties. Authors can identify during medical education which student will be at risk of professional burnout after studies. Thus there could be a selection of interventions directed toward differentiated groups of students, e.g.: supplying them with proper coping vs. guiding them, to increase life satisfaction and productivity. Int J Occup Med Environ Health 2018;31(6):823-835
\end{abstract}

Key words:

Medical students, Medical career, Physicians, Burnout, Occupational satisfaction, Medical education

\section{INTRODUCTION}

This paper reports 10-year longitudinal data from a project designed to describe the role of values during medical education and to clarify their linking to styles of success within 4 years of graduation.

The Rokeach developed a theoretical perspective on the nature of values in a cognitive framework and a value- measurement instrument [1]. Rokeach defined the value concept as "an enduring belief that a specific mode of conduct or end-state of existence is personally or socially preferable to an opposite or converse mode of conduct or end-state of existence" [1, p. 5]. The Rokeach Value Survey (RVS) distinguishes 2 sets of values. Terminal values concern desirable end-states (such as freedom, inner

\footnotetext{
Funding: this research was supported by Medical University of Gdańsk, Poland (grant No. ST-50\#1998-2000 entitled "Psychosocial determinants of failures and successes in the implementation of student tasks," grant manager: Waldemar Budziński; grant No. ST-50\#2001-2003 entitled "Mechanisms and personality traits and dynamics of their changes in medical students," grant manager: Waldemar Budziński; grant No. ST-50\#2004-2006 entitled "The importance of selected psychological properties for the stability and effectiveness of mental functioning in students of the last two years of medical studies," grant manager: Waldemar Budziński; grant No. W-139\#2009-2010 entitled "Psychological aspects of adaptation to the medical profession - factors determining success in the medical career," grant manager: Maciej Walkiewicz).

Received: November 1, 2017. Accepted: March 7, 2018.

Corresponding author: Maciej Walkiewicz, Medical University of Gdańsk, Faculty of Psychology, Tuwima 15, 80-210 Gdańsk, Poland (e-mail: maciej.walkiewicz@gumed.edu.pl).
} 
harmony or national security) while instrumental values express modes of conduct or virtues (ambitious, honest, polite) [1,2].

Gorsuch [3] has finally noted that "the final distinction" the instrumental one - is not sharp enough as "each value that is not absolutely the highest, may be perceived as an instrumental value." However, it is worth defining all terminal values as related exclusively to idealized terminal states of existence and all instrumental values as those related exclusively to Gorsuch. The publication of Rokeach's book "The Nature of Human Values" caused a surge of empirical studies which investigated the role of human values in many branches of psychology and sociology. In the last decades, human values have been investigated in divergent scientific domains such as political ideology [1], personality assessment [4], moral reasoning [5], or process and out - come of psychotherapy [6].

The medical students declare reasons for their decision to take up medicine as a career tended to endorse social/ altruistic reasons (working with people, helping others) and the opportunity to become involved in a challenging occupation. These are the most important reasons for their occupational choice. Other explanations, such as satisfying parents' ambitions or possibility to achieve high social status and financial stability, are rated much lower in importance [7]. In comparison with females, male medical students tend to rate personal, agentic reasons as more important, and interpersonal, expressive reasons as less important. The students' value priorities are related in predictable ways to the importance ratings they assigned to particular reasons, especially to status/materialistic reasons [7]. Medical students' value hierarchies seem to be similar in different countries. In English speaking countries such as Australia [7] and the UK [8]: loving, honest, helpful, broadminded and responsible are at the top of the hierarchy of instrumental values.

What is more, the medical students tend to rank inner harmony, mature love, and helpfulness higher in relative im- portance when compared with the students of psychology course. They also seem to rank a comfortable life, freedom and ambitions as lower in relative importance [7]. What is more, other results of students' value hierarchy have shown that: business students presented higher priorities to power and achievement values, social science students presented higher priorities to universalism values, and technology students - to security values [9]. Hierarchy of values of medical students show that 3 most important terminal needs are "health," "love" and "family happiness." Three most important instrumental needs are "breeding," "education" and "honesty." The least important terminal needs are "creativity," "pleasure" and "a world of beauty." Finally the least important instrumental needs in medical students are "intolerance," "ambition" and "independence" [10]. Medical education puts students under a lot of pressure, giving a large volume of material to be mastered, ensuing heavy workload as well as lack of time for regeneration [11]. The classic study by Becker and Geer [12] on "the fate of idealism in medical school" saw this stress as sometimes leading to a sort of disillusionment with the initial idealistic professional ideology. Some reports suggest that medical schools do not necessarily promote developmental progress due to heavy emphasis on natural sciences in the curriculum, combined with a rote learning approach to studies [13]. Moreover, they provide so few role-taking opportunities that, as a consequence, the students regress in their moral judgement. At the same time, they learn to express the medical student value profile outside. The traditional medical schools did not promote moral reasoning skills [14].

Moral reasoning in medical students has not indicated any advancement over the 4 years of study [15]. Medical students tend to score higher moral reasoning than average college students, however the research conducted on practicing medical doctors suggests that moral reasoning does not develop much after medical school [16]. Self and Baldwin prove that many studies demonstrate the lack of 
Medical students

(admission and 6 years of studies)

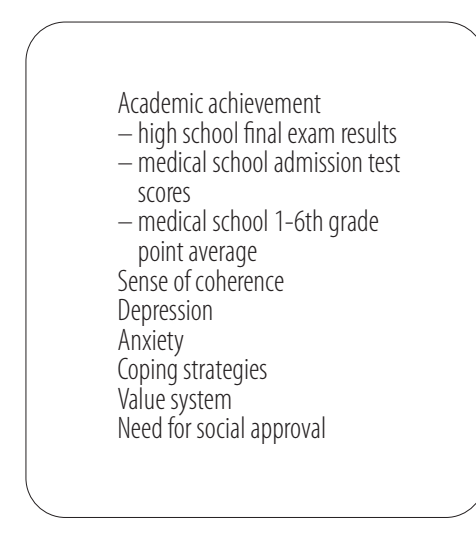

Medical doctors

(resident doctors -4 years after graduation)

Fig. 1. Model of success predictors and markers of success 4 years after graduation (10-year longitudinal study)

increase in moral reasoning and moral development generally expected in this age group and suggesting a possible inhibiting effect of this educational experience [15,17].

The research has provided some evidence that there is no unarguable model that would describe the concept of a success in the medical career. The longitudinal study presenting information about the quality of life of Polish physicians was an inspiration to develop our model of success in the medical career [18]. Thus, the background of this specific model was based on well-being and life satisfaction, including some complementary factors mentioned by Gattiker and Larwood in their model of career success, such as a job success (performance, happiness at work) and financial success [19]. Having reviewed the literature, authors decided to include work stress and burnout as symptoms of difficulty and failure in response to job expectations and as important measures of success in the medical career [20-23]. In the previous paper the authors of the article determined that success in a medical career seemed to be the consequence of the personality characteristics and not a simple result of the medical education process [24]. Authors also identified 3 styles, based on significant differences between them in terms of postgraduate medical competence, satisfaction with medicine as a career, work stress and burnout, and the quality of life (Figure 1). Authors have termed this first style
"Committed - satisfied with career," as it refers to those physicians who are the most committed to their work and manifested the highest level of work stress and tendency to burnout. The "Clever - satisfied with life" is the least committed to their work, but they derive the most benefit from it. The "Bright - competent" could be characterized as the most competent, nevertheless, they have problems with managing their lives [25-27].

The presented study was designed to describe the role of the system values during medical education in determining styles of occupational success in a medical career within 4 years after graduation, basing on our model of success.

\section{MATERIAL AND METHODS}

\section{Participants}

The first part of the study took place a few days before the admission test. All individuals who had applied to the Medical University of Gdańsk, Poland, received a letter with questionnaires ( $\mathrm{N}=365$ of 940,39\% response rate). Only those who had passed the admission exam were taken into consideration for the purposes of our research $(\mathrm{N}=320,65 \%$ female). The procedure was repeated subsequently at the end of every academic year. Over a period of 4 years after graduation, the authors cooperated with institutions responsible for postgraduate medical education 
Table 1. The response rates of medical students and doctors (10-year longitudinal study)

\begin{tabular}{lc}
\hline \multicolumn{1}{c}{ Study period } & $\begin{array}{c}\text { Participants } \\
(\mathrm{N}=320)\end{array}$ \\
\hline Admission & 178 \\
First year & 178 \\
Second year & 129 \\
Third year & 127 \\
Fourth year & 121 \\
Fifth year & 58 \\
Sixth year & 138 \\
Medical doctors 4 years after medical study & 54 \\
\hline
\end{tabular}

in Poland. Access to the results of the postgraduate State Examination for Medical Doctors ( $\mathrm{N}=268$ of 320, an 84\% response rate) was obtained and the addresses of 255 medical doctors, who had participated in the first part of the study, were found. The response rate in this group was $21 \%$ $(\mathrm{N}=54)$. The mean age of respondents was $29.5 \pm 0.8$ years (69\% female). The response rates are shown in Table 1.

\section{Measures}

Independent variable

The Rokeach Value Survey [1] presents respondents with 2 sets of 18 values. The first set, called the terminal values, refers to general goals or "end-states of existence" (e.g., equality, family security, self-respect). The second set, called the instrumental values, refers to means or "modes of conduct" (e.g., being capable, helpful, self-controlled). The 18 values in each set (terminal, instrumental) are arranged alphabetically and the terminal values are presented first. The respondent is asked to rank each set of 18 values in their order of importance for self, "as guiding principles in your life." The rank order from 1 - most important to 18 - least important is achieved by rearranging the gummed labels within each set. One therefore obtains a rank order for the terminal values 1-18 and a rank order for the instrumental values 1-18 [1,2].

\section{Dependent variables}

Three styles of success in a medical career were identified based on significant differences between them in terms of:

- postgraduate medical competence,

- satisfaction with medicine as a career,

- work stress and burnout,

- quality of life [25-27].

\section{Postgraduate medical competence}

The first parameter of success in medical career was measured by examination results on the State Examination for Medical Doctors, supplied by the Medical Examination Centre in Poland. This exam is administered during the postgraduate internship, and it is required to gain a license to practice medicine. The results determine whether or not further medical specialization will be possible. The exam is organized by the Medical Examination Centre every spring and autumn. The exam starts at the same moment in 11 districts in Poland. It is a multiple choice test. The subject matter includes: internal medicine, pediatrics, surgery, gynecology and obstetrics, psychiatry, family medicine, emergency medicine and intensive care, oncology, bioethics and medical law, public health, medical jurisdiction. The success rate was determined by the number of points obtained in the State Examination for Medical Doctors. The higher result the higher success.

\section{Satisfaction with medicine as a career}

The second parameter of success in a medical career was measured by a self-designed survey based on the Cantril's Scale method, where 1 meant "very low" and 10 meant "very high" (Cronbach's $\alpha=0.8 ; \mathrm{r}=0.67$ ).

The questions were: "Please specify on the scale below what satisfaction of your choice of profession you expected during your studies"; “...how you currently evaluate satisfaction from choosing a profession"; “...how you assess the expected satisfaction from choosing a profession for 5 years". 


\section{Work stress and burnout}

The third parameter of success in a medical career was measured by the Maslach Burnout Inventory (MBI) adapted by Pasikowski, which had 3 sub-scales: Emotional exhaustion, Depersonalization, and Personal accomplishment. The tool is characterized by good psychometric properties [28,29].

\section{Quality of life (QOL)}

The fourth parameter of success in a medical career was measured by a questionnaire derived from "Social diagnosis: Objective and subjective quality of life in Poland" [18]. Quality of life consisted of:

- General well-being and health. It consists of 2 different questions (Cronbach's $\alpha=0.74, \mathrm{r}=0.40$ ):

- "taking under the consideration your life during last 2 weeks, could you say it was: unhappy; not happy; quite happy; very happy";

- "taking under the consideration your whole life, could you say it was: awful; unhappy; not very successful; neither good nor bad; pretty good; successful; great)."

- Life satisfaction was measured by 22 questions about different aspects of human life, e.g., social, financial, quality of life surroundings and health. The question was: "Please assess the individual aspects of your life, and say how much are you satisfied of them: 1 - very satisfied; 2 - satisfied; 3 - quite happy; 4 - quite dissatisfied; 5 - dissatisfied; 6 - very dissatisfied; 0 - not applicable" (Cronbach's $\alpha=0.83 ; \mathrm{r}=0.25$ ).

- Size of income. To determine the size of income, the question about „Average total monthly income” was asked:

- PLN $<1000$,

- PLN 1000-2000,

- PLN 2000-3000,

- $\mathrm{PLN}>3000$.

\section{Statistics}

All the statistical methods authors used were exploratory in nature, so that the use of subsequent analyses was dependent on the previous outcomes. In the earlier phase of our research, the cluster analysis was used for identifying styles (clusters) of success. In the presented study the ANOVA analysis of variance was used for determining the differences between clusters during studies, cross checking with the coping strategies. In order to reduce this error in the third step, authors used the discriminant analysis (with the backward method using Ward's estimate). The predictors were variables from ANOVA, and the dependent variables were styles of success (clusters).

\section{RESULTS}

For the purpose of better organizing the obtained data authors divided the study period into the preclinical period: $0-2$ years and the clinical period: $3-6$ years.

\section{The "Committed"}

The first style called the "Committed - satisfied with career," those most involved in their work are under the highest level of work stress as well as vulnerability to burnout. Actually, the "Committed" clearly declare the lowest terminal value "family security" (year 1-6). They also display the lowest level of "freedom" value, especially in the second and the third year of studies. However, they declare the highest level of the variable "self-respect" both in preclinical and clinical period (year 2-6), the highest level of "wisdom" in clinical years (year 3 and 4 ) and "mature love" in the final year of their studies (year 6). Moreover, in the area of instrumental value, that is the ways of obtaining their life goals, the "Committed," within the whole period of their studies, manifest the highest value of the "self-control" variable (year 0-6). What is more, starting from - more or less - the second half of their study period, they clearly declare the highest level of such variables as: "forgiving" (year 4-6) and "responsible" (year 3 and 6) and the lowest at the end of their studies "honest" and "capable" (year 5 and 6). 


\section{The "Clever"}

The "Clever" show the lowest level of the terminal "wisdom" value during their study period (year 0-4) and the highest "family security" in the clinical years (year 2-6). In the area of instrumental values they declare the lowest values of self-control during their studies (year 0, 1, 4, 5 ) and the lowest of "independent": in pre-clinical years (year 0 and 1), "obedient" (year 3 and 4), "courageous" (year 3-5), and the lowest "loving" (year 4-6). Furthermore, as practicing physicians, they are resistant to burnout, have the highest quality of life and income, display a low level of postgraduate competence, and the least satisfaction with their chosen career. They presumably may not be overly engaged, and may also have other life priorities and values. That is why they are not in the group exposed to the risk of burnout.

\section{The "Bright"}

The physicians who are the most competent, have difficulties with governing their lives. They have been called the "Bright - competent." The "Bright" declare the highest level of terminal value "self-respect" during studies (year 2, 5, 6), the highest level of "wisdom" at the beginning of their studies (year 0 and 1 ) and the highest level of "mature love" in the final years (year 5 and 6). In the area of instrumental values the "Bright" feature the lowest values of "forgiving" (year 4-6) and the highest of "honest" (year 5 and 6).

The terminal values are shown in the Table 2, instrumental values in the Table 3.

\section{DISCUSSION}

This article has been the attempt to find answers to very important research questions: Do the empirically found types of medical career are connected to the declared hierarchies of values of the individuals representing these types? Another question concerns the dynamics of changes in the declared hierarchies of values occurring through studying. On the basis of the obtained results, they may help formulate the following conclusions.

The identified 3 groups of students representing 3 types of careers have been different regarding their preferred terminal values. The differences have comprised the values such as: family security, freedom, happiness, mature love, self-respect, social recognition and wisdom. The most relevant differences have been found in the groups of the "Committed - satisfied with career" vs. the "Clever - satisfied with life" and the "Committed - satisfied with career" vs. the "Bright - competent."

Although the "Committed" who have manifested higher satisfaction with medicine as a career than the other groups, have obtained the lowest results in postgraduate competence examinations, they appreciate the "self-respect" value more than the others. However, the "family security" values have been lower in their hierarchy.

The results may imply that a doctor's role is especially important to this group and contributes to a high level of "self-respect." Altruistic values such as due care of the family, are less important to them.

Whereas the "Clever" who have declared low level of satisfaction with medicine as a career and have achieved lower results in postgraduate competence examinations, they have been more satisfied with their life as well as their income. They also have valued "family security" higher and "wisdom" lower than other groups. It seems that the doctors who belong to this group highly appreciate family goals and values and are less focused on their own career and development. The "Bright" have valued more "mature love" and "wisdom." They have achieved the highest professional competences but presented a low level of satisfaction with medicine as a career and with the quality of their life. The students of this group, determined with the value of "wisdom," have been focused on their professional competences, but their efforts have brought neither life satisfaction nor "self-respect." They have also valued "mature love" more the other groups. 


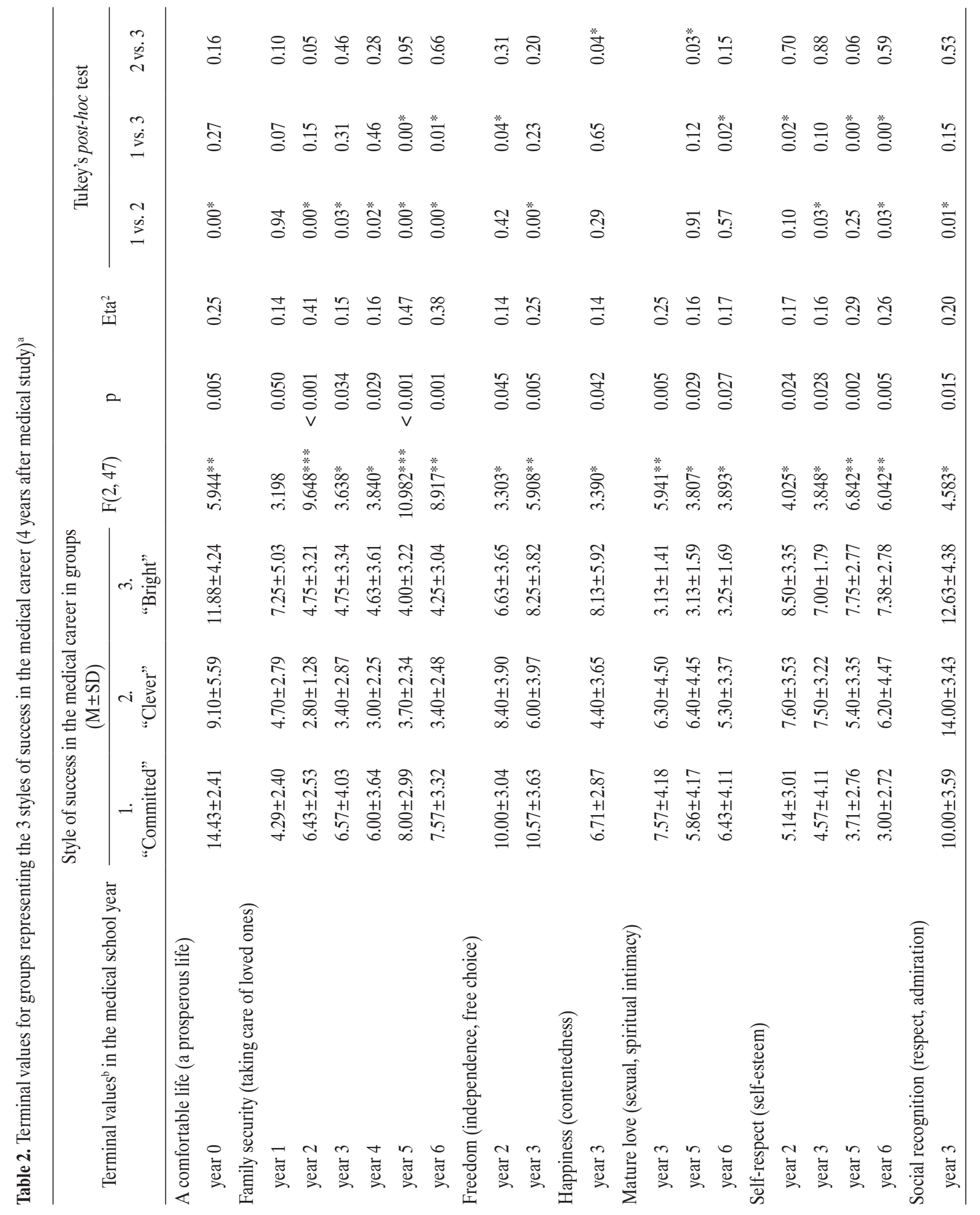



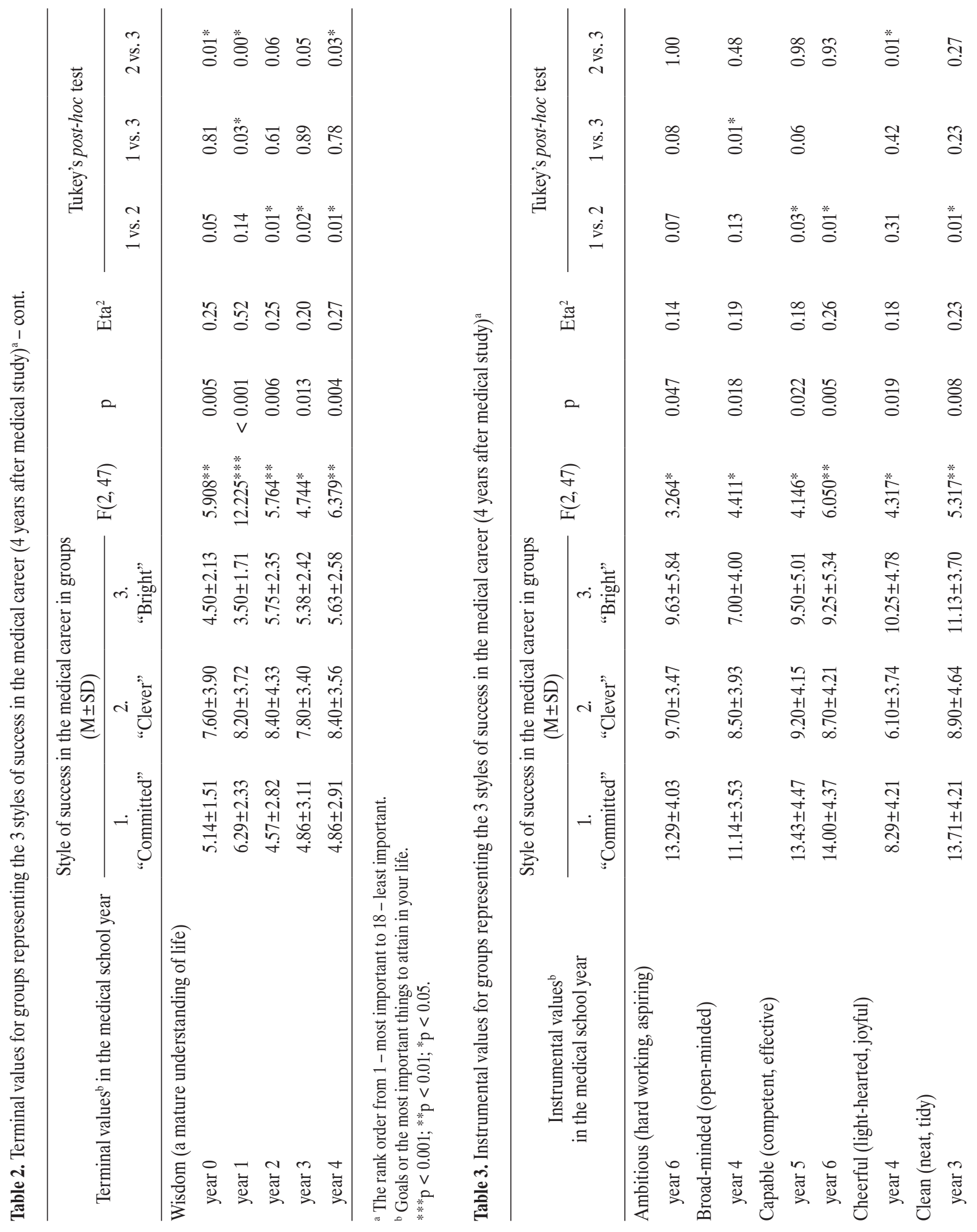


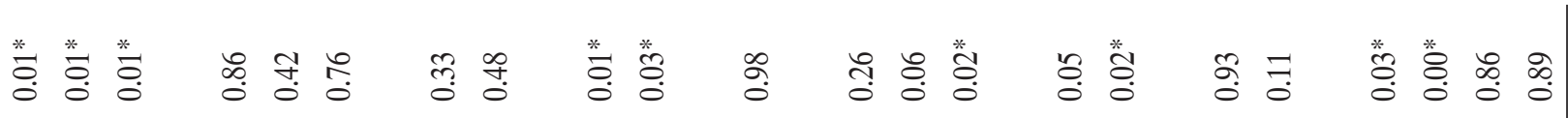

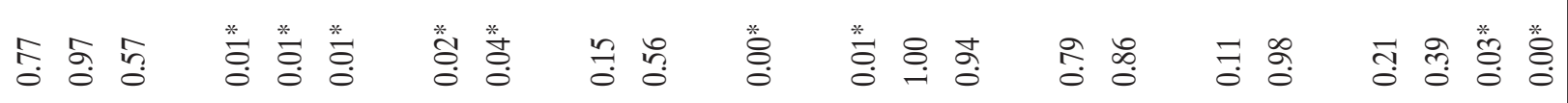

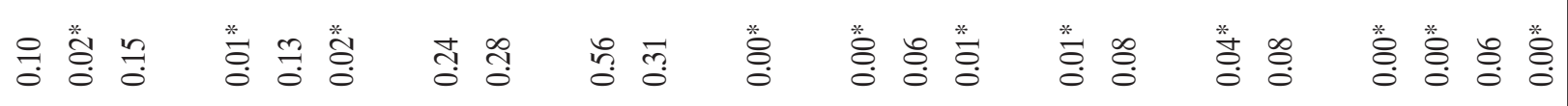

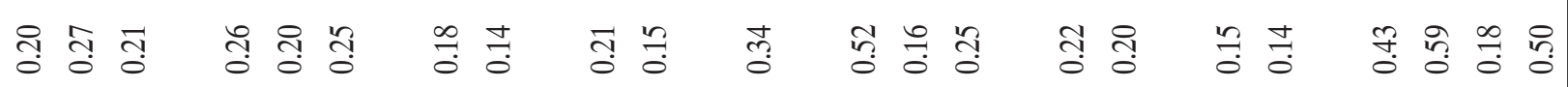

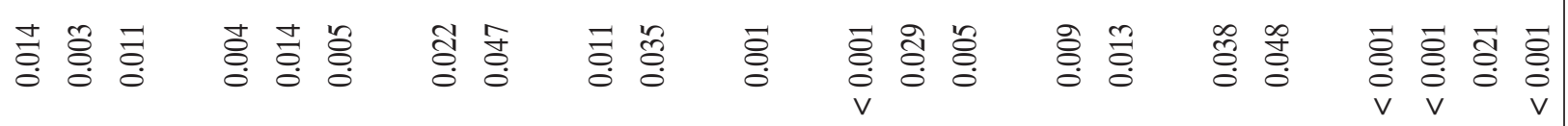

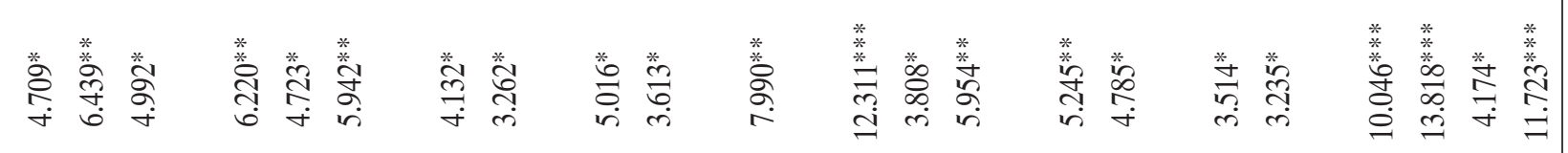

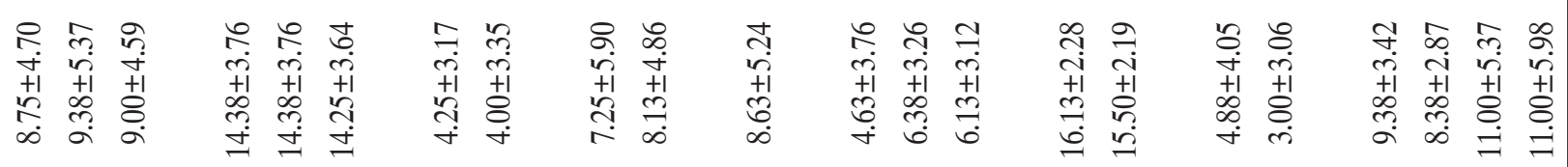

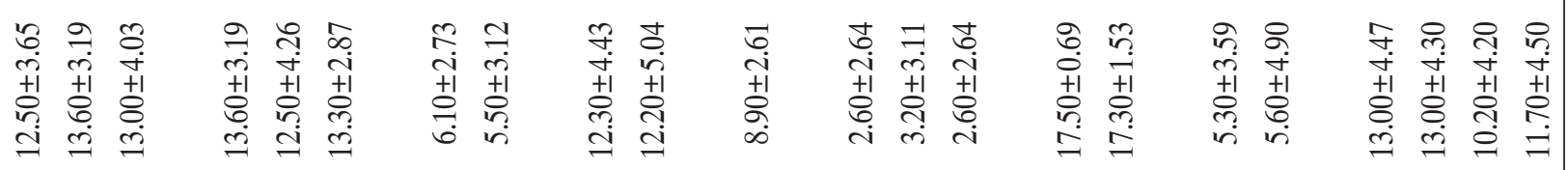
可哥去

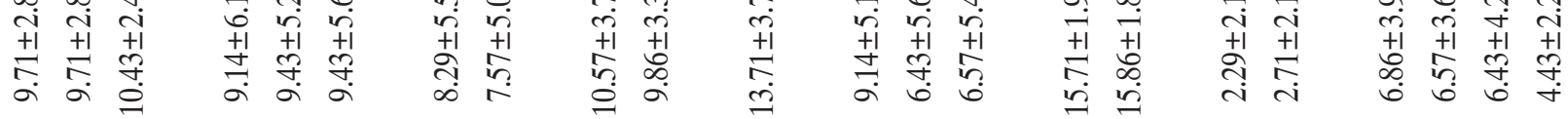

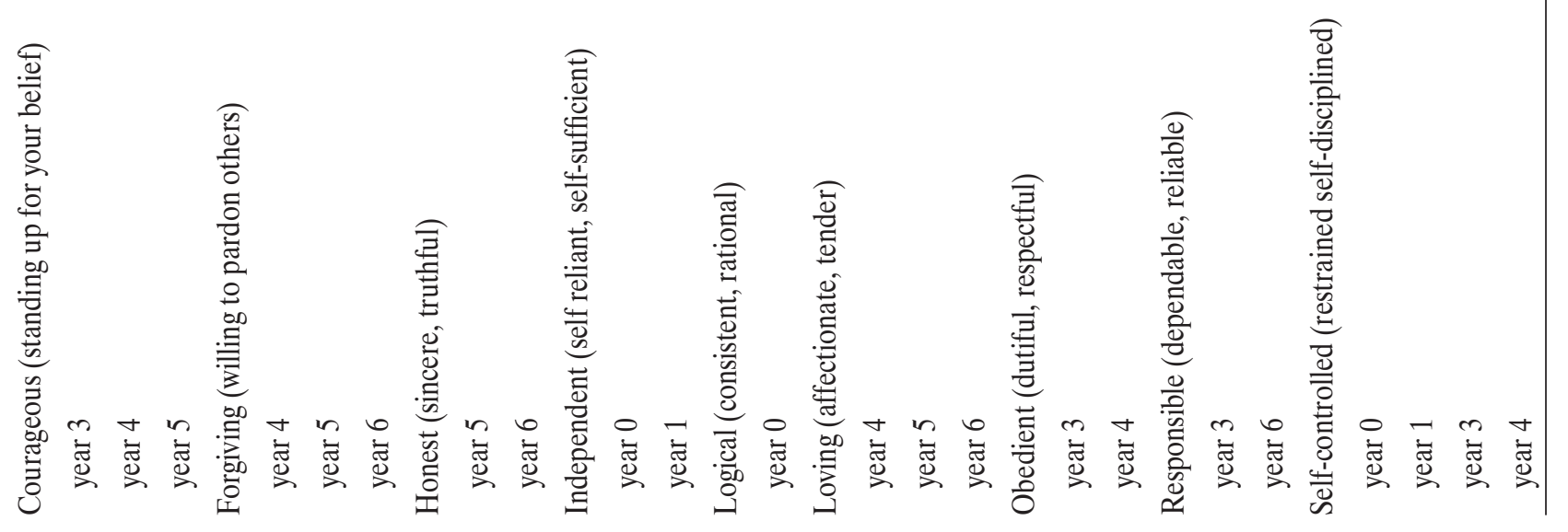




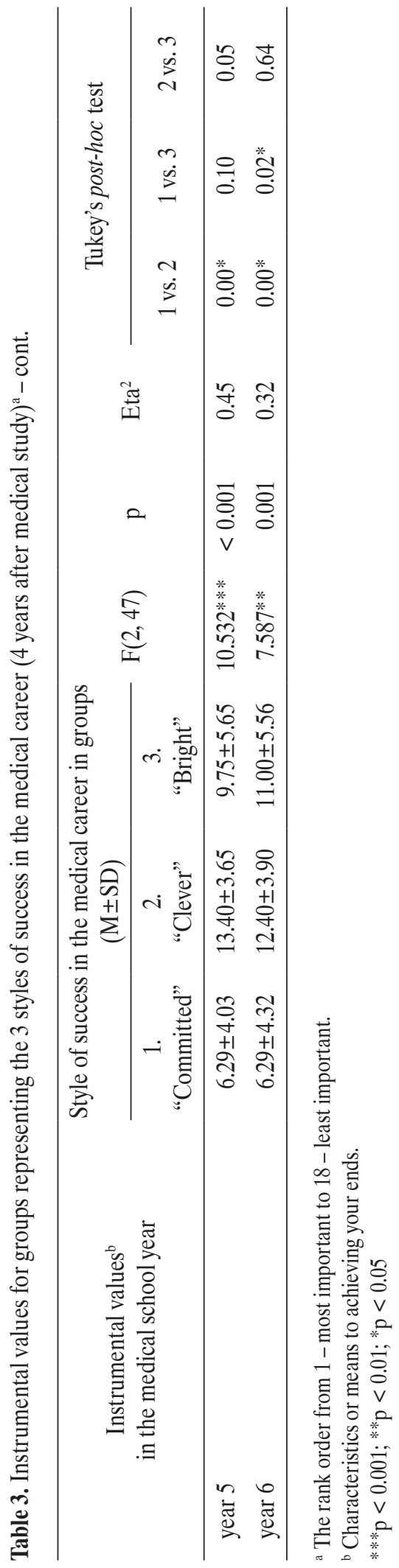

Their desire for "mature love" presumably may not have been fulfilled as they declare low level of life satisfaction. Their efforts towards obtaining higher competences (than the others) during their studies have brought neither greater life satisfaction nor decent income. The hierarchies of instrumental values have been more differentiated than the hierarchies of terminal values. This conclusion concerns mostly the clinical years of studying (year 3-6). These hierarchies are also more dynamic (changeable) within the course of studies.

Instrumental values are less stable in the first years of studies. The achieved results prove the thesis that terminal values are relatively stable whereas instrumental values tend to change within the life course and life circumstances. Authors may formulate a hypothesis that it is easier to determine clear life goals than to find the proper methods for obtaining them.

When considering the hierarchy of instrumental values it may be noted that the "Committed" have appreciated "self-control" value higher the other groups.

Probably, by applying this value they have stronger feeling of achievement and freedom of choice and this may bring higher satisfaction with medicine as a career and income (Table 4).

\section{CONCLUSIONS}

The study identified 3 types of future physicians. Significant level of predictability in identifying which student will follow which path provides an opportunity for guidance. Out of 3 groups, 2 of them present a high risk of burnout. The "Committed" physicians seem to have sacrificed their personal life for their careers. Yet, it has not brought them satisfaction. They are excellent and most dedicated physicians. They bring great value to their profession. However, they are limited by their level of stress and facing the risk of burnout. Medical schools may consider identifying appropriate interventions targeting those students. Equipping them with applicable coping strategies may increase their life satisfaction as well as productivity. 
Table 4. Styles of success in medical career and system values during studies - summary of the 10-year longitudinal study

\begin{tabular}{|c|c|c|c|}
\hline \multirow[b]{2}{*}{ Values } & \multicolumn{3}{|c|}{ Style of success in the medical career in groups } \\
\hline & $\begin{array}{c}1 . \\
\text { "Committed" }\end{array}$ & $\begin{array}{c}2 . \\
\text { "Clever" }\end{array}$ & $\begin{array}{c}3 . \\
\text { "Bright" }\end{array}$ \\
\hline \multicolumn{4}{|l|}{ Terminal } \\
\hline family security (taking care of loved ones) & $\downarrow \mathrm{P} \downarrow \mathrm{C}$ & $\uparrow P \uparrow C$ & \\
\hline freedom (independence, free choice) & $\downarrow P$ & & \\
\hline happiness (contentedness) & & $\uparrow P$ & $\downarrow P$ \\
\hline mature love (sexual, spiritual intimacy) & & & $\uparrow \mathrm{C}$ \\
\hline self-respect (self-esteem) & $\uparrow P \uparrow C$ & & $\downarrow \mathrm{P} \downarrow \mathrm{C}$ \\
\hline wisdom (a mature understanding of life) & $\uparrow \mathrm{C}$ & $\downarrow \mathrm{P} \downarrow \mathrm{C}$ & $\uparrow P$ \\
\hline \multicolumn{4}{|l|}{ Instrumental } \\
\hline self-controlled (restrained, self-disciplined) & $\uparrow P \uparrow C$ & $\downarrow \mathrm{P} \downarrow \mathrm{C}$ & \\
\hline capable (competent, effective) & $\uparrow \mathrm{C}$ & & \\
\hline courageous (standing up for your belief) & & $\downarrow \mathrm{C}$ & $\uparrow \mathrm{C}$ \\
\hline forgiving (willing to pardon others) & $\uparrow \mathrm{C}$ & & $\downarrow \mathrm{C}$ \\
\hline honest (sincere, truthful) & $\downarrow \mathrm{C}$ & & $\uparrow \mathrm{C}$ \\
\hline independent (self-reliant, self-sufficient) & & $\downarrow P$ & $\uparrow P$ \\
\hline logical (consistent, rational) & $\downarrow \mathrm{P}($ year 0$)$ & & \\
\hline loving (affectionate, tender) & & $\uparrow \mathrm{C}$ & \\
\hline obedient (dutiful, respectful) & & $\downarrow \mathrm{C}$ & \\
\hline responsible (dependable, reliable) & $\uparrow \mathrm{C}$ & & \\
\hline
\end{tabular}

P - preclinical years of study (0-2); C - clinical years of study (3-6).

The "Clever" group may be the one in no need for specific intervention. Although least committed to their work, they are qualified physicians. They find happiness and satisfaction outside of their profession and continue serving with low risk of burnout.

The "Bright" group is the most competent. That does not provide them with career satisfaction, proportionate income, or life satisfaction, either. This group will likely present as successful students during their years of academic life. They are not expected to struggle with academic demands. However, they may be most in need of guidance. Perhaps pairing with seasoned physicians for mentorship could be an appropriate intervention.
Lastly, data confirms that terminal values are relatively stable, but instrumental values are likely to change. $\mathrm{Fu}-$ ture research may investigate how medical schools may support students in identifying instrumental values that will promote their life satisfaction.

\section{ACKNOWLEDGMENTS}

We are very grateful to our respondents for taking part in our research. We would like to thank Prof. Mikołaj Majkowicz, of the Faculty of Psychology Medical University of Gdańsk, Poland, for general support; Prof. Mariusz Klencki, of the Medical Examination Centre, Poland, for his permission to analyze the examination results of postgraduates; and Krzysztof Wójcikiewicz M.D., of the Polish Chamber of Physicians in Gdańsk for organizational help. 


\section{REFERENCES}

1. Rokeach M. Beliefs, attitudes, and values: A theory of organization and change. San Francisco: Jossey-Bass; 1968.

2. Rokeach M. The nature of human values. New York: Free Press; 1973.

3. Gorsuch R. Rokeach's approach to value systems and social compassion. Rev Relig Res. 1970;11(2):139-43.

4. Heaven PCL. Personality predictors of self-reported delinquency. Pers Individ Dif. 1993;14(1):67-76, https://doi. org/10.1016/0191-8869(93)90175-3.

5. Weber J. Exploring the relationship between personal values and moral reasoning. Hum Relat. 1993;46(4):435-63, https:// doi.org/10.1177/001872679304600402.

6. Kelly TA. The role of values in psychotherapy: A critical-review of process and outcome effects. Clin Psychol Rev. 1990;10(2):171-86, https://doi.org/10.1016/0272-7358 (90)90056-G.

7. Feather NT. Reasons for entering medical school in relation to value priorities and sex of student. J Occup Psychol. 1982;55(2):119-28, https://doi.org/10.1111/j.2044-8325.1982. tb00084.x.

8. Furnham A. Values and vocational choice: A study of value differences in medical, nursing and psychology students. Soc Sci Med. 1988;26(6):613-8, https://doi.org/10.1016/02779536(88)90025-1.

9. Myyry L, Helkama K. University students' value priorities and emotional empathy. Educ Psychol. 2001;21(1):25-40, https://doi.org/10.1080/01443410123128.

10. Iskra N, Moskvicheva N. Values and research potential in students of medical and human sciences. Procedia Soc Behav Sci. 2014;112:252-9, https://doi.org/10.1016/j.sbspro. 2014.01.1162.

11. Niemi PM, Vainiomaki PT. Medical students' academic distress, coping, and achievement strategies during the preclinical years. Teach Learn Med. 1999;11(3):125-34, https:/doi. org/10.1207/S15328015TL110302.

12. Becker HS, Geer B. The fate of idealism in medical school. Am Sociol Rev. 1958;23(1):50-6.
13. Lindblom-Ylaanne S, Lonka K. Students' perceptions of assessment practices in a traditional medical curriculum. Adv Health Sci Educ Theory Pract. 2001;6(2):121-40, https:/doi. org/10.1023/A:1011422517238.

14. Helkama K, Uutela A, Pohjanheimo E, Salminen S, Koponen A, Rantanen-Vantsi L. Moral reasoning and values in medical school: A longitudinal study in Finland. Scan J Educ Res. 2003;47(4):399-411, https://doi.org/10. 1080/00313830308589.

15. Self DJ, Schrader DE, Baldwin DC, Wolinsky FD. The moral development of medical students: A pilot study of the possible influence of medical education. Med Educ. 1993;27(1):26-34, https://doi.org/10.1111/j.1365-2923.1993. tb00225.x.

16. Rest JR. Moral development: Advances in research and theory. New York: Praeger; 1986.

17. Self DJ, Baldwin DC, Jr. Moral reasoning in medicine. In: Rest JR, Narva EZD, editors. Moral development in the professions. Hillsdale: Erlbaum; 1994.

18. Czapiński J, Panek T. [Social diagnosis 2015. Objective and subjective quality of life in Poland - Report]. Contemp Econ. 2015;9(4). Polish.

19. Gattiker UE, Larwood L. Subjective career success: A study of managers and support personnel. J Bus Psychol. 1986;1(2):78-94, https://doi.org/10.1007/BF01018805.

20. Ferguson E, James D, Madeley L. Factors associated with success in medical school: Systematic review of the literature. BMJ. 2002;324(7343):952-7, https://doi.org/10.1136/ bmj.324.7343.952.

21. Edwards JA, Guppy A, Cockerton T. A longitudinal study exploring the relationships between occupational stressors, non-work stressors, and work performance. Work Stress. 2007;21(2):99-116, https://doi.org/ 10.1080/02678370701466900.

22. Schaufeli WB, Bakker AB, van der Heijden F, Prins JT. Workaholism, burnout and well-being among junior doctors: The mediating role of role conflict. Work Stress. 2009;23(2): 155-72, https://doi.org/10.1080/02678370902834021. 
23. Woloschuk W, McLaughlin K, Wright B. Is undergraduate performance predictive of postgraduate performance? Teach Learn Med. 2010;22(3):202-4, https://doi.org/10.1080/ 10401334.2010.488205.

24. Tartas M, Walkiewicz M, Majkowicz M, Budzinski W. Psychological factors determining success in a medical career: A 10-year longitudinal study. Med Teach. 2011;33(3):e16372, https://doi.org/10.3109/0142159X.2011.544795.

25. Walkiewicz M, Tartas M, Majkowicz M, Budzinski W. Academic achievement, depression and anxiety during medical education predict the styles of success in a medical career: A 10-year longitudinal study. Med Teach. 2012;34(9): e611-9, https://doi.org/10.3109/0142159X.2012.687478.

26. Tartas M, Walkiewicz M, Budzinski W, Majkowicz M, Wojcikiewicz K. The sense of coherence and styles of success in the medical career: A longitudinal study. BMC Med Educ. 2014;14:254, https://doi.org/10.1186/s12909-014-0254-5.

27. Tartas M, Walkiewicz M, Budzinski W, Majkowicz M, Wojcikiewicz K, Zdun-Ryzewska A. The coping strategies during medical education predict style of success in medical career: A 10-year longitudinal study. BMC Med Educ. 2016;16:186, https://doi.org/10.1186/s12909-016-0706-1.

28. Maslach C, Jackson S. Maslach Burnout Inventory. Palo Alto: Consulting Psychologists Press; 1986.

29. Pasikowski T. [Polish adaptation of the Maslach Burnout Inventory]. In: Sęk H, editor. [Occupational burnout. Causes, mechanisms, prevention]. Warszawa: Wydawnictwo Naukowe PWN, 2000. p. 135-48. Polish.

This work is available in Open Access model and licensed under a Creative Commons Attribution-NonCommercial 3.0 Poland License - http://creativecommons.org/ licenses/by-nc/3.0/pl/deed.en. 